
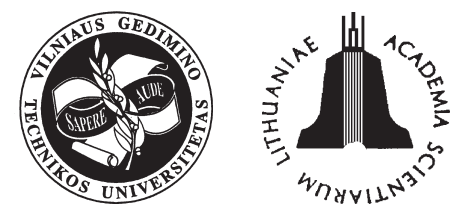

ISSN 1648-4142 TRANSPORT

http:/www.vtu.lt/english/editions

\title{
EXPERIMENTAL INVESTIGATION OF THE BRAKING PROCESS OF AUTOMOBILES
}

\author{
Edgar Sokolovskij \\ Dept of Transport Technological Equipment, Faculty of Transport Engineering, \\ Vilnius Gediminas Technical University, \\ Plytinès g. 27, LT-10105 Vilnius-16, Lithuania.E-mail: ESokolovskij@hotmail.com
}

Received 2005-01-07; accepted 2005-03-15

\begin{abstract}
The present article depicts the results of investigation of the braking parameters of automobiles equipped with ABS and without ABS. The values of the automobile deceleration, the increase of the deceleration time and the time of disbraking while braking on a dry asphalt-concrete surface which was fixed in the course of the experimental investigation are presented. The dependence of deceleration of automobiles equipped with ABS and without ABS upon the primary driving speed is reflected and substantiated. The results of the investigation of braking of automobiles equipped with ABS and without ABS under winter conditions, i.e. on ice and snow are presented.
\end{abstract}

Keywords: automobile, ABS, braking, dynamics, experimental investigation.

\section{Introduction}

It is a usual case when the values of braking parameters fixed for the automobiles of previously manufactured models are specified in the literary sources [1]. However, these values do not usually suit modern automobiles. The values of braking parameters of automobiles specified in some sources do not suit the modelling of automobile movement. For example, the values of deceleration of automobiles specified by the manufacturers of automobiles and tires are usually fixed for the phase of the most efficient braking, not having evaluated certain constituents of the braking process as a result of which the larger values are obtained. These values suit the advertising and comparison of products. However, for modelling of automobile movement (for example, for the examination of traffic accidents), the values of average, settled deceleration are necessary $[1,2]$. Moreover, in the course of investigation of the braking process the deceleration of transport vehicles and the braking track are usually fixed. However, the other parameters such as the time of deceleration increase and the time of disbraking are also important in the course of examination of traffic accidents.

Recently the items of the usage of antilock brake systems (ABS) installed in automobiles are often considered both in scientific and popular literature [39]. However, till nowadays not all the problems have been solved. The results of the investigation of the braking parameters and peculiarities of automobiles provided with ABS and of automobiles without it are specified below [10].

\section{Methods and conditions of the experimental inves- tigation}

The experimental investigation has been carried out under following conditions:

- the cars equipped with an antilock brake system (ABS) and without it which were produced in the years 1986-2000 have been used for investigation;

- the cars were in a good technical condition and equipped with the factory (non-substituted) brake system;

- two people served as the load of the tested cars, i.e. the driver and the "passenger" who was taking care of the measuring device (the decelerometer);

- $\quad$ the same person was driving the car in the course of all the tests;

- the cars were equipped with the tires of the size which is recommended for this particular type of the model; the depth of the protector notch was not less than $3 \mathrm{~mm}$. The cars equipped with the summer tires have been tested on a dry surface of the asphalt road, whereas the cars equipped 
with the winter non-prickly tires have been tested under winter conditions (on snow and ice);

- the air pressure of the tires was nominal for the definite model of the car and its load;

the tests have been carried out on the horizontal stripe of a non-rough asphalt road where there was no traffic, by calculating the mean number afterwards;

- the tests have been carried out in both directions - not less than three tests in each case, by calculating the mean number afterwards;

- in the course of the investigation of dependence of the deceleration upon the car primary speed the tests on a dry surface of the asphalt road have been carried out with the cars equipped with ABS which have been driven at the primary speed of $60 \mathrm{~km} / \mathrm{h}, 80 \mathrm{~km} / \mathrm{h}$ and $100 \mathrm{~km} / \mathrm{h}$, and with the cars without $\mathrm{ABS}$ which have been driven at the speed of $30 \mathrm{~km} / \mathrm{h}, 50 \mathrm{~km} / \mathrm{h}$ and $80 \mathrm{~km} / \mathrm{h}$ (for the sake of safety the tests with the cars without ABS have been carried out at the smaller primary speed);

- for the sake of safety in the course of the investigation of the influence of ABS functioning upon the car deceleration under winter conditions the cars driven at the primary speed of $30 \mathrm{~km} / \mathrm{h}$. have been tested under winter conditions (on snow and ice).

Measurements have been taken with the help of an electronic device which measures the deceleration, i.e. decelerometer VZM 100 (Fig 1).

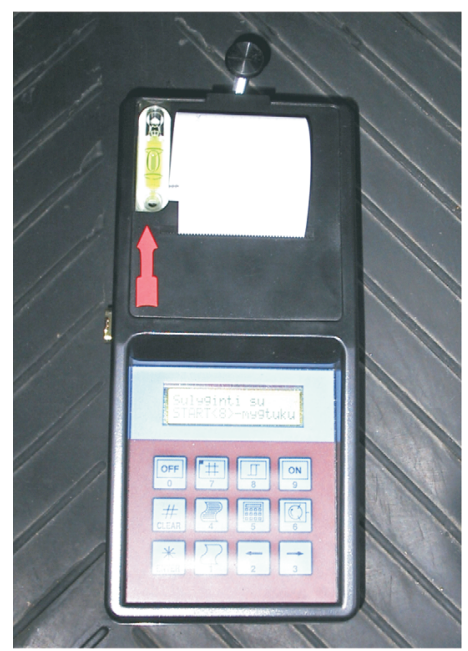

Fig 1. Decelerometer VZM 100

\section{Results of the experimental investigation}

At first the dependence of deceleration of the vehicles without ABS upon the primary speed has been investigated. The results of the investigation are presented in Fig 2.

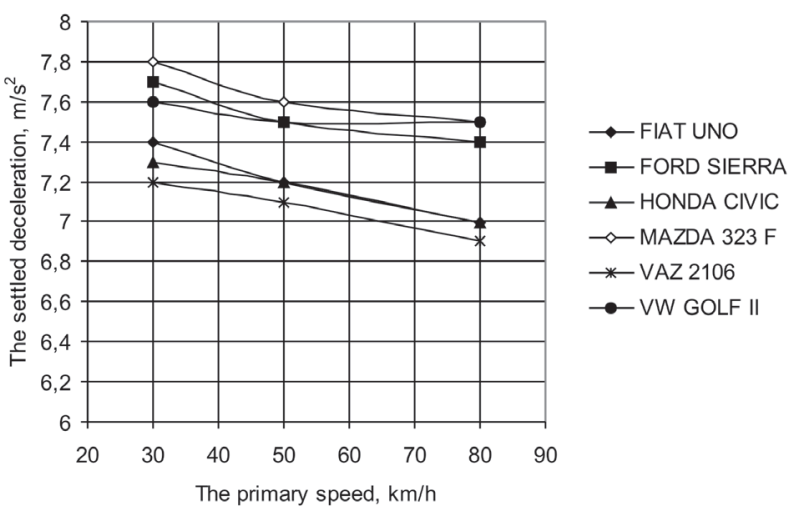

Fig 2. Dependence of the deceleration upon the primary speed holding up the vehicles without ABS

As we see the deceleration of the vehicle without ABS decreases with the increase of the primary speed.

The analogous investigation has been carried out with holding up the vehicles equipped with ABS. The results of these investigations are presented in Fig 3 .

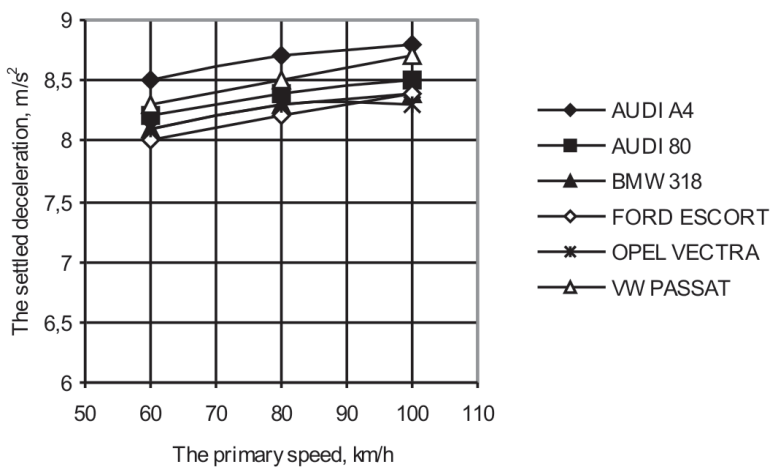

Fig 3. Dependence of the deceleration upon the primary speed holding up the vehicles equipped with ABS

It should be stated that in the course of testing the average settled deceleration of all the vehicles equipped with $\mathrm{ABS}$ on a dry surface of the asphalt road was not less than $8 \mathrm{~m} / \mathrm{s}^{2}$ - it was within the limits from $8 \mathrm{~m} / \mathrm{s}^{2}$ up to $8,8 \mathrm{~m} / \mathrm{s}^{2}$. The vehicle deceleration at the stage of the most efficient braking in most cases used to exceed $9 \mathrm{~m} / \mathrm{s}^{2}$, sometimes it used to reach the deceleration value of a free fall $\left(9,81 \mathrm{~m} / \mathrm{s}^{2}\right)$.

In the course of investigation it was observed that while holding up the vehicles equipped with ABS, sometimes it is difficult to notice visually the traces of braking of the wheels (especially under certain lighting conditions). However, in most cases the length of the remaining traces is shorter than the length of the brake-path.

It was ascertained that, while holding up the vehicles equipped with $\mathrm{ABS}$, the deceleration does not decrease. It even increases with the increase of the 
primary speed of the vehicle. So to explain the abovestated situation we shall compare the diagrams of braking in both cases (Fig 4).

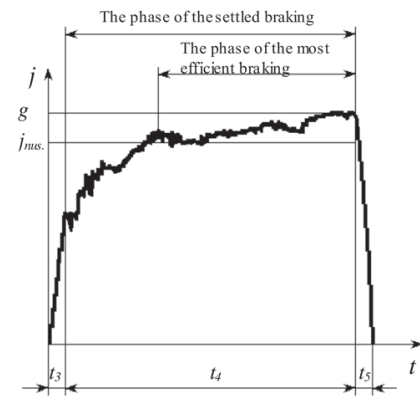

a)

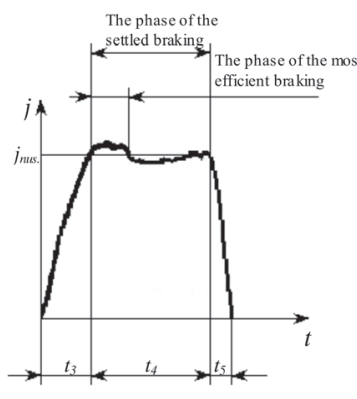

b)
Fig 4. The diagrams of braking: a - the vehicle equipped with ABS, $b$ - the vehicle without ABS

As it is seen from the diagram of braking the deceleration of the vehicle without ABS, which is in a good technical condition reaches its peak in very beginning of braking till the vehicle wheels remain unblocked. When the wheels become blocked the deceleration decreases to a certain extent as, actually, holding up of the blocked wheel is less efficient (Fig $4, \mathrm{~b})$. Thus, in the course of holding up the vehicle without ABS, when the vehicle is driven at a lower speed the above-mentioned peak of deceleration makes the larger part of the whole process of braking and v.v. the peak makes the smaller part of the process of braking when the vehicle is driven at a higher speed and the process of braking takes longer time. Besides, the other factors such as heating of the tire gum of the blocked wheel of the automobile in the contact zone, etc., are also significant. The deceleration decrease typical of the vehicles which are driven at the increasing primary speed can be explained by this fact. It should be stated that not always the "classic" diagrams of braking reflecting the peak of maximal deceleration down while starting to brake were obtained in the case of braking the automobiles without ABS.

In the course of holding up the vehicles equipped with ABS, (according to the principle of ABS functioning, the wheels remain unblocked within the whole period of braking), there is no deceleration peak in the beginning of braking. On the contrary, in the course of holding up the vehicles equipped with ABS when the wheels interact with the surface of the road (ABS controls the situation and prevents the wheel sliding to exceed a certain value - usually appr. $20 \%$ ), the deceleration continues to increase insignificantly in the course of further braking after the phase of increase of the deceleration. Thus, a bit smaller decel- eration values are reached in the beginning of braking, whereas the largest values are usually reached when the process of braking becomes stable at the end of braking. The deceleration increase with the increase of the primary speed of the vehicle equipped with ABS can be explained by this fact (Fig 4, a).

Besides, the values of the time of deceleration increase $t_{3}$ and of the time of disbraking $t_{5}$ have been ascertained in the course of investigation. The obtained results are presented in Table 1.

Table 1. The time of deceleration increase $t_{3}$ and the time of disbraking $t_{5}$

\begin{tabular}{|l|c|c|c|}
\hline \multicolumn{1}{|c|}{ Vehicle } & ABS & $\begin{array}{c}\text { Time of } \\
\text { deceleration } \\
\text { increase } t_{3}, \mathrm{~s}\end{array}$ & $\begin{array}{c}\text { Time of } \\
\text { disbraking } \\
t_{5}, \mathrm{~s}\end{array}$ \\
\hline AUDI A4 & + & 0,1 & 0,1 \\
\hline AUDI 80 & + & 0,15 & 0,1 \\
\hline BMW 318 & + & 0,15 & 0,1 \\
\hline FIAT UNO & - & 0,2 & 0,15 \\
\hline FORD ESCORT & + & 0,15 & 0,15 \\
\hline FORD SIERRA & - & 0,2 & 0,1 \\
\hline HONDA CIVIC & - & 0,25 & 0,15 \\
\hline MAZDA 323 F & - & 0,2 & 0,1 \\
\hline OPEL VECTRA & + & 0,15 & 0,15 \\
\hline VAZ 2106 & - & 0,3 & 0,2 \\
\hline VW GOLF II & - & 0,2 & 0,1 \\
\hline VW PASSAT & + & 0,1 & 0,1 \\
\hline
\end{tabular}

As we see, the values of the time of deceleration increase $t_{3}$ of all the vehicles which have been investigated have not exceeded $0,3 \mathrm{~s}$. The maximal $0,3 \mathrm{~s}$ value was typical of the car VAZ 2106. The values of the time of deceleration increase $t_{3}$ of most of the Japanese and western vehicles have not exceeded $0,2 \mathrm{~s}$ and remained within the limits of $0,1 \div 0,2 \mathrm{~s}$. Only very oldfashioned vehicles make an exception. In this case it was a 15-year old car HONDA CIVIC the value of the time of deceleration increase of which made $0,25 \mathrm{~s}$.

The values of the time of disbraking $t_{5}$ specified in certain literary sources which have been published earlier did not prove (for the hydraulic brake system $\left.t_{5}=1,5 t_{3}\right)$. The values of the time of disbraking obtained in the course of investigation, did not exceed the values of the time of deceleration increase and were within the limits of $0,1 \div 0,15 \mathrm{~s}$, except the car VAZ 2106 with the time of disbraking equal to $0,2 \mathrm{~s}$.

Besides, the tests of holding up of the vehicles equipped with $\mathrm{ABS}$ and without it have been carried out under winter conditions, i.e. on ice and snow. In our case these were the cars FORD ESCORT (equipped with ABS) and FORD SIERRA (without ABS). The obtained results are presented in Table 2.

In the course of investigation it was ascertained that slightly larger deceleration was typical of the vehicle equipped with ABS (FORD ESCORT), in the course of its holding up on ice. 
Table 2. Deceleration of the vehicles equipped with ABS and without it under winter conditions

\begin{tabular}{|l|c|c|}
\hline $\begin{array}{c}\text { Surface of the } \\
\text { road fit for } \\
\text { traffic }\end{array}$ & $\begin{array}{c}\text { Average deceleration } \\
\text { of the vehicle } \\
\text { equipped with ABS } \\
\text { (FORD ESCORT), } \\
\mathrm{m} / \mathrm{s}^{2}\end{array}$ & $\begin{array}{c}\text { Average } \\
\text { deceleration of the } \\
\text { vehicle without } \\
\text { ABS (FORD } \\
\text { SIERRA), } \mathrm{m} / \mathrm{s}^{2}\end{array}$ \\
\hline Ice & 2,0 & 1,8 \\
\hline Snow & 2,6 & 3,0 \\
\hline
\end{tabular}

A bit different results have been obtained while holding up the vehicles equipped with ABS and without it on the snowy surface of the road fit for traffic. In this case slightly larger deceleration was typical of the vehicle without ABS (FORD SIERRA). Such unexpected results can be explained by the fact that the blocked wheels of the vehicle without ABS contact a wet surface of the asphalt road covered with a thin layer of snow thus stipulating the deceleration increase. Besides, the blocked wheels push and thicken the snow in front of them. Thus, the area of the wheel bearing increases and the effect similar to holding up the vehicle on a soft surface (for example, soft soil) shows itself.

The wheels of the vehicle, equipped with ABS remain unblocked. Thus, they do not contact the wet surface of the asphalt road and the deceleration is smaller. However, it should be stressed that in any case including the case with holding up the vehicle on snow (though in this case the deceleration of the vehicle equipped with $\mathrm{ABS}$ was a bit smaller), ABS distinguishes by significant positive influence upon the operation of the vehicle as the possibility to drive it remains. This is very important for the traffic security as most of the traffic accidents occur due to the absence of possibility to operate the vehicle.

\section{Conclusions}

1. In the course of braking the vehicles equipped with $\mathrm{ABS}$ on a dry surface of the asphalt road the average settled deceleration used to be within the limits from $8 \mathrm{~m} / \mathrm{s}^{2}$ up to $8,8 \mathrm{~m} / \mathrm{s}^{2}$. In most cases the deceleration used to exceed $9 \mathrm{~m} / \mathrm{s}^{2}$ in the phase of the most efficient braking. The values of time of the deceleration increase $t_{3}$ typical of the vehicles equipped with $\mathrm{ABS}$ used to be within the limits $0,1 \div 0,15 \mathrm{~s}$. The values of time of disbraking $t_{5}$ did not exceed the time values of the deceleration increase and used to be within the limits $0,1 \div 0,15 \mathrm{~s}$.

2. The average settled deceleration of the vehicles without ABS while holding them up on a dry surface of the asphalt road used to be within the limits from $6,9 \mathrm{~m} / \mathrm{s}^{2}$ up to $7,8 \mathrm{~m} / \mathrm{s}^{2}$. The values of time of the deceleration increase $t_{3}$ used to be within the lim- its $0,2 \div 0,3 \mathrm{~s}$. The values of time of disbraking $t_{5} \mathrm{did}$ not exceed the time values of the deceleration increase and used to be within the limits $0,1 \div 0,2 \mathrm{~s}$.

3. It was ascertained that while holding up the vehicles equipped with $\mathrm{ABS}$ the average settled deceleration increases with the increase of the primary speed of the vehicle, whereas in the case of holding up the vehicles without ABS it decreases (Figs 2 and 3 ). This significant difference typical of the vehicles equipped with ABS and the vehicles without it is reflected in the diagrams of braking (Fig 4).

4. Having carried out the experimental investigation under winter conditions it was ascertained that the automobile equipped with ABS was held up on ice more efficiently (approximately 10\%). The vehicle without ABS was held up on a snow-covered surface of the road more efficiently (approximately 13\%) because in this case the blocked wheels of the vehicle without ABS contact the wet surface of the asphalt road, push and thicken the snow in front of them. However, in any case, ABS plays a significant positive role in the operation (control) of the vehicle as the possibility to drive the vehicle remains.

5. There is a possibility to model the vehicles movement and to restore the course of the traffic accidents more precisely while carrying the examination of the traffic accidents. However, it is necessary to use the fixed values of braking parameters of automobiles while evaluating the technical condition of the definite automobile as in certain cases (for example, dealing with old automobiles) these values can be unsuitable.

\section{References}

1. Ilarionov, V. A. Examination of road traffic accidents (Экспертиза дорожно-транспортных происшествий). Moscow: Transport, 1989. 254 p. (in Russian).

2. Lukoševičienè, $O$. The accident analysis and simulation. Monograph (Autoịvykių analize ir modeliavimas. Monografija). Vilnius: Technika, 2001. 244 p. (in Lithuanian).

3. Ahlgrimm, J.; Grandel, J. Evaluation of traffic accident to cars with Antilock Brake System (ABS). Traffic accident and automobile technics (Verkehrsunfall und Fahrzeugtechnik), No 3, 1997, p. 67-74 (in German).

4. Bogdevičius, M.; Prentkovskis, O.; Vladimirov, O. Engineering solutions of traffic safety problems of road transport. Transport, 2004, Vol XIX, No 1, p. 43-50.

5. Danner, M.; Halm, J. Technical analysis of road accidents (Technische Analyse von Verkehrsunfällen). Eurotax (International) AG CH-8808 Pfäffikon, 1994. 570 p. (in German).

6. Mills, V.; Samuel, B.; Wagner, J. Modelling and Analysis of Automotive Antilock Brake Systems to Vehicle 
Payload Shifting. Vehicle System Dynamics, Vol 37, No 4, 2002, p. 283-310.

7. Sherman, D. The ABCs of ABS. Popular Science, Vol 252, No 6, 1998, p. 75-79.

8. Donges, E. A Conceptual Framework for Active Safety in Road traffic. Vehicle System Dynamics, Vol 32, No $2 /$ 3, 1999, p. 113-128.

9. Lewandowski, A. The factors which influence the quality of braking of the automobile with ABS In: Proceedings of the $7^{\text {th }}$ Conference „Problems of reconstruction of road traffic accidents" (7 konferencja. Problemy rekonstrukcji wypadków drogowych. Krakow, 11-12 September, 2000. K: IES, p. 227-237 (in Polish).

10. Sokolovskij, E. Investigation of interaction of the wheel with the road and its elements in the context of examination of traffic accidents. Doctoral Dissertation (Rato sąveikos su keliu ir jo elementais tyrimai eismo ịvykių ekspertizès kontekste. Daktaro disertacija). Vilnius: VGTU, 2004. 147 p. (in Lithuanian). 